\title{
Predictive model of the dam foundation deformations according to the consolidation model
}

\author{
Alexander Bakshtanin, and Margarita Shiryaeva* \\ RSAU - Moscow Agricultural Academy named after K.A. Timiryazev, Moscow, Russia
}

\begin{abstract}
The dam with two culverts on the Vyunka river has been chosen for forecasting calculations. The physical and geographical features of the research area have been explored. The information on the organization of the control system of the hydraulic structure has been studied, the mix of diagnostic indicators of the state of the hydraulic structures substantiation has been carried out. The calculated values of the coefficients of the overall the upstream and downstream slopes stability for the cases considered have exceeded the standard coefficient of stability. The criteria values of the diagnostic indicators at the project stage have been defined by analysing the calculation results with ultimate element technique using the Plaxis 2D program for filtration modes, stress-strain state, strength and stability of hydraulic structures for the main and special combinations of loads. The choice of indicators is based on assessing the possibility of monitoring their values. The influence of the type of damage and destruction of the above elements has different significance on the hydraulic structures' safety. A predictive model of deformations of the dam base was built according to the consolidation model based on the extrapolation method. The results of the obtained model of research hydraulic stricture are given.
\end{abstract}

\section{Introduction}

A prerequisite for the diagnostic control of dams is the development of predictive mathematical models in accordance with the adopted "methodology for determining the safety criteria for hydraulic structures" and the recommendations of the federal law. With the development and evolution of numerical survey methods and calculating means there appeared the opportunity to survey the condition of structures on the new more detailed level.

The created models of tense deformation condition of hydraulic structures due to actual loads: hydrostatic pressure, temperature, seepage condition etc. describe in details the condition of structures from field studies data. However, one should be careful to use them to predict deformations $[1,2]$.

The purpose of this study is to create a predictive model of deformations of the dam's foundation and body according to the consolidation model. The object is the dam with two culverts on the Vyunka in located in the village of Novy Milet of Moscow Oblast.

\footnotetext{
* Corresponding author: margaretshiryaeva@gmail.com
} 


\section{Materials and methods}

The Vyunka River is of a flat type, the mouth is located in the Pekhorka River. Vyunka belongs to the Oka basin district, the Oka river basin, the water management area is Moscow from the Zaozerye railway station to Kolomna. The Chernaya River in the Balashikha District joins the Vyunka River and forms the Chernavka River, the left inflow of the Pekhorka River. The Chernaya River is $14 \mathrm{~km}$ long. It starts near the village Novaya, $4 \mathrm{~km}$ east of the town of Balashikha, merges with Vyunka $2 \mathrm{~km}$ south of the town Zheleznodorozhny. The hydraulic structure's geographic coordinates (degrees, minutes, seconds) are $55^{\circ} 40^{\prime} 51^{\prime \prime} \mathrm{N}$, $38^{\circ} 01^{\prime} 4$ " E (Fig.1).

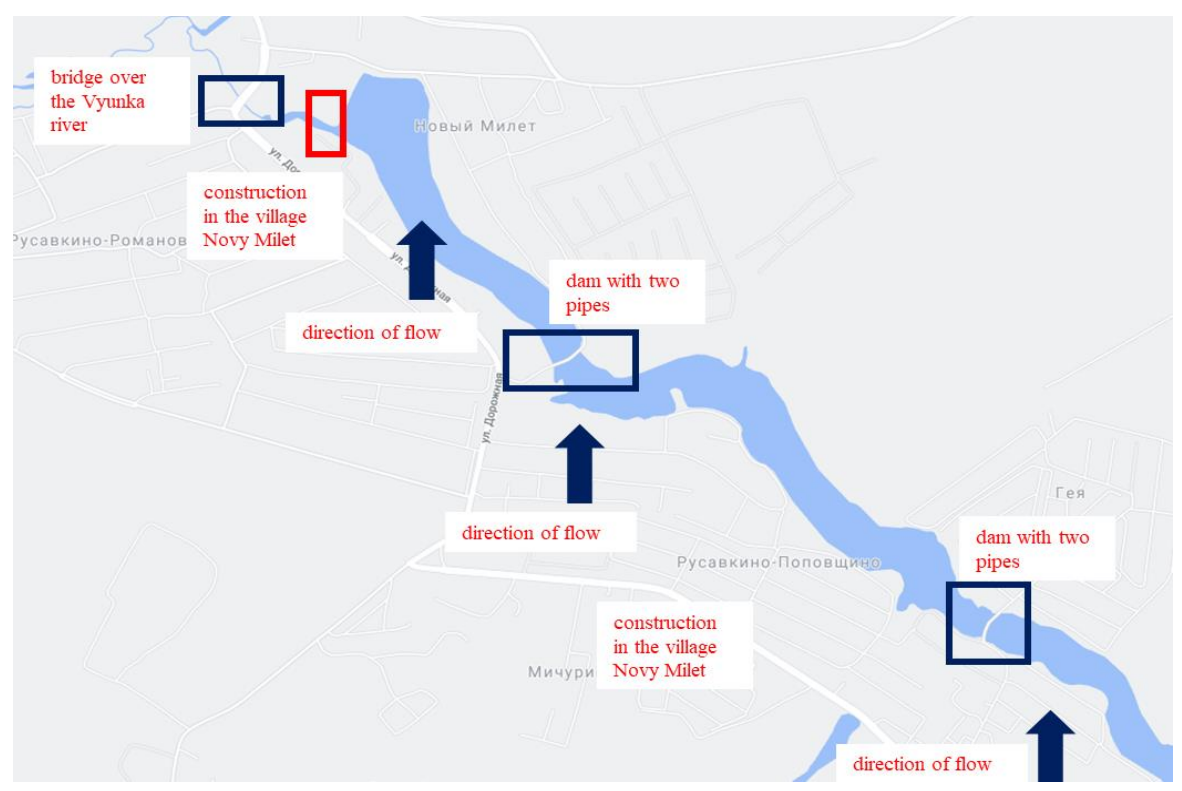

Fig. 1. Dam location on the Vyunka River.

\subsection{The climate}

The climate is temperate-continental, with well-defined seasons of particularly moderately warm and humid summers and cold winters with stable snow cover. The climate is influenced by the air masses of the Atlantic Ocean. The western and south-eastern winds prevail. During the year, western and southern cyclones pass through the territory. The sum of active average daily air temperatures is 1900-2100 degrees, the average annual rainfall varies greatly from year to year and, according to long-term observations, is $500-650 \mathrm{~mm}$. The average annual humidity is about $78 \%$. The average annual air temperature over a long period is $+5.6{ }^{\circ} \mathrm{C}$. The average monthly temperature in July is $+16.9^{\circ} \mathrm{C}$, in January $-6.3{ }^{\circ} \mathrm{C}$. The warm period with a positive average daily temperature lasts an average of 215-220 days. The frost-free period lasts 135-145 days.

The flood begins on April 4-15 and ends on April 28 - May 25, lasts from 20 to 45 days. The river freezes in late November, opening in early April. The thickness of the ice is from 30 to $70 \mathrm{~cm}$. The area under the dam is a trapezoidal floodplain with terraces. The river has a fairly wide straight channel $30 \mathrm{~m}$ to the place of turning to the west. The catchment area is 
asymmetric, pear-shaped. The width of the floodplain is up to $1 \mathrm{~km}$. Water levels are presented in Fig.2.

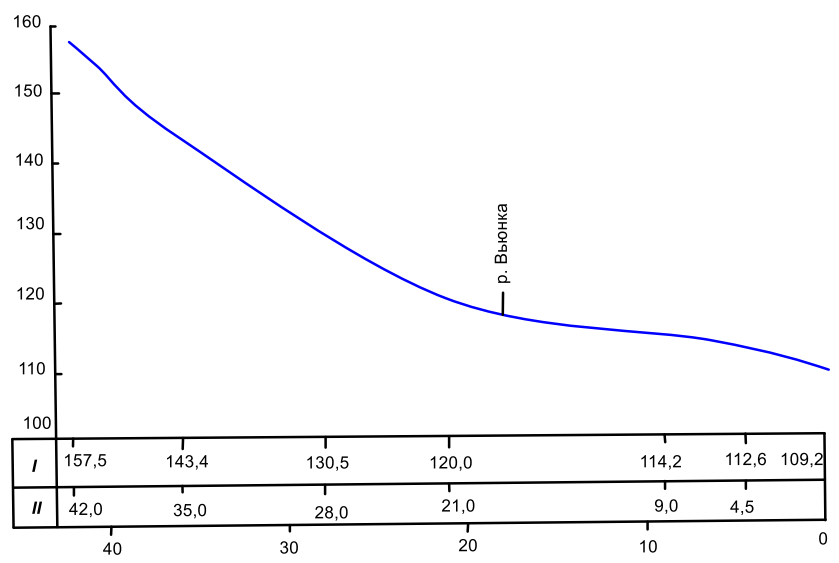

Fig. 2. Water levels in the Vyunka river.

\subsection{Dam description}

The hydraulic structure includes the following elements:

- the dam that blocks the river and part of the floodplain;

- coastal landfalls, slopes of the diversion channel with a protective covering with reinforced concrete slabs;

- gate chamber with 2 shutter valves, apron, water section from a toothed sill, reinforced concrete service bridge with handrails, mechanical equipment for gate control.

To determine the composition of the diagnostic indicators of structure's the state, we have chosen 4 types of structures:

-the dam, its foundation;

-landfalls, slopes;

-reinforced concrete hydraulic structures, gate chamber;

-the dam gates $[6,7]$.

When choosing the composition of indicators, the possibility of monitoring their values has been assessed. The influence of the type of damage and destruction of the above elements has different implications for the safety of hydraulic structures. Lists of diagnostic indicators are given in the standards [3-5].

Taking into account the recommendations of the above documents, for this low-pressure dam of a pond in the village Novy Milet, the composition of the state of the hydraulic system diagnostic indicators has been selected, for which criterial values have been determined [8, 9].

The frequency of measures to control indicators is once every 5 years, during the survey period of the dam. It is recommended to install water-measuring rods on the side of the upstream and downstream of the waterworks for level measurement (measurement error 5 $\mathrm{mm}$ ). Other indicators can be measured during investigations with portable devices. Measurement techniques are given in the relevant Interstate standard and other standards. follows:

The critical deformation under the conditions of the plane problem is defined as

$$
\varepsilon_{\text {кр }}=\left(\varepsilon_{\text {дл }}+\varepsilon_{\text {рг }}\right) *(1-
$$




\section{$\left.\mu^{2}\right)$}

$\varepsilon_{\text {дл }}-$ long-term ultimate soil extensibility;

$\varepsilon_{\mathrm{p} \Gamma}-$ continuous discharging of compressive deformation stresses created own soil weight;

$\mu$ - Poisson coefficient equal to 0.37 .

\section{Research results}

The criterial values of the diagnostic indicators at the project stage have been determined based on the analysis of the results of calculations by the finite element method using the Plaxis 2D program of filtration modes, stress-strain state, strength and hydraulic structures sustainability for the main and special combinations of loads [10].

The calculations have made it possible to determine the sustainability criteria for the dam upstream and downstream slopes, check the general and local stability of the slopes of the dam with varying water levels in the upstream and downstream of the dam for the following design cases [11].

The water level in the upstream is equal to the normal retaining level (NRL), the level of the downstream is $0.9 \mathrm{~m}$, and the filtration is steady for the upstream and downstream slopes. The soils physical and mechanical characteristics correspond to the summer period of exploitation. Calculations for a particular combination of loads have been carried out at a water level in the upstream equal to the forced backwater level (FBL).

The calculated values of the coefficients of the overall stability of the dam upstream and downstream slopes for the cases considered have exceeded the standard coefficient of sustainability.

Settlement criteria for the dam body elements are determined based on the analysis of the dam coping measurements data. The criteria for the dam coping total settlement have made it possible to assess the sufficiency of the excess and the gates elements above the water levels in the pond.

The K2 values of the depression curve position have determined from the results of filtration calculations of the depression curve position and the dam slopes sustainability for the section with the minimum value of the sustainability coefficient.

The results of calculations using the Plaxis 2D are shown in Fig. 3. 

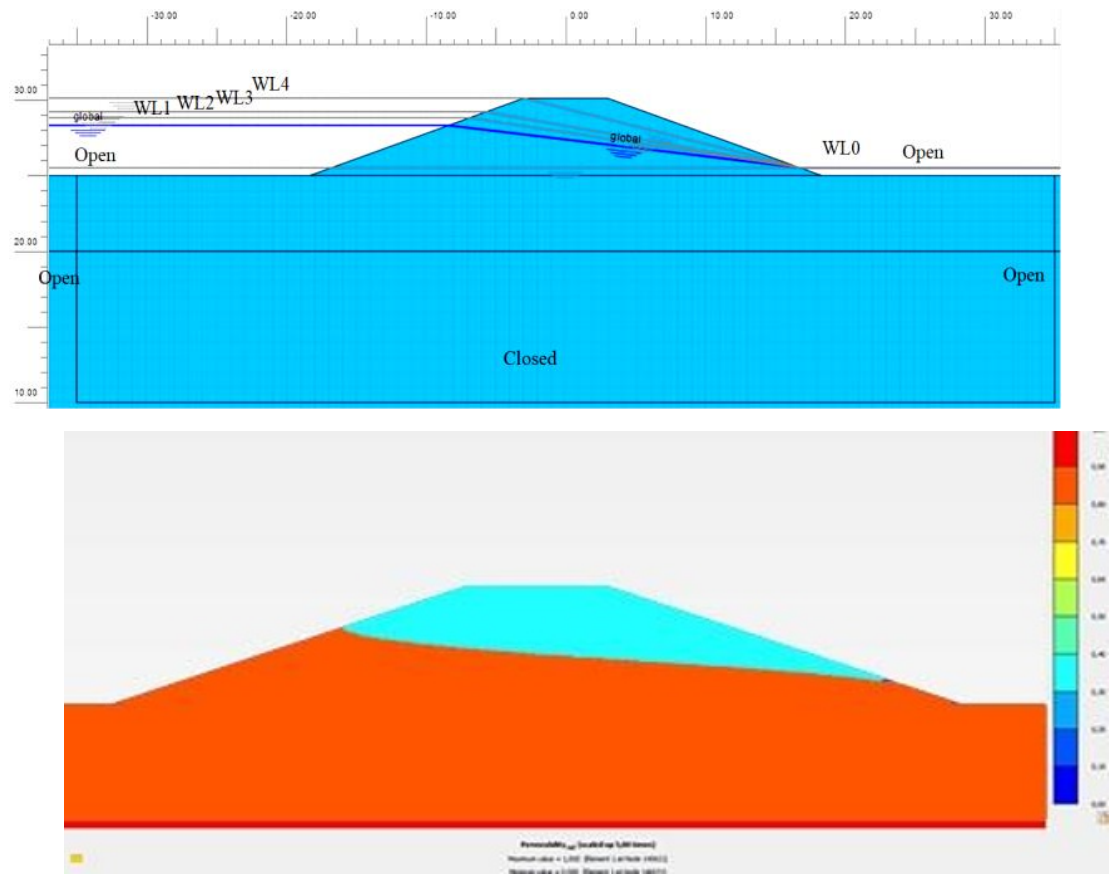

Fig. 3. The result of the calculations. Calculated diagram dam and depression curve on the depth equal to 3.7 meters.

Equally distributed load at the dam-foundation boundary along the dam width of $50 \mathrm{kN}$ $/ \mathrm{m} / \mathrm{m}$ from the gate chamber weight. Kulon-Mohr model has been adopted. The calculations have been carried out according to the Plastic and Safety schemes. The soils characteristics under drainage conditions are given below.

Table 1. Considered characteristics.

\begin{tabular}{|c|c|c|c|c|}
\hline \multirow{2}{*}{$\begin{array}{c}\text { characteristic } \\
\text { Material }\end{array}$} & \multirow[b]{2}{*}{ dimension } & \multicolumn{2}{|c|}{ foundation } & \multirow{2}{*}{$\begin{array}{c}\text { Structure } \\
\text { technogenic } \\
\text { soil }\end{array}$} \\
\hline & & $\begin{array}{l}\text { Clay } \\
\text { loam }\end{array}$ & $\begin{array}{c}\text { sandy } \\
\text { loam }\end{array}$ & \\
\hline runsat & кН/ $\mathrm{m}^{3}$ & 19.60 & 20.40 & 19.60 \\
\hline$\gamma_{\text {sat }}$ & кН/ $/ \mathrm{M}^{3}$ & 19.77 & 20.60 & 19.77 \\
\hline ein & - & 0.720 & 0.595 & 0.720 \\
\hline $\mathrm{v}$ & - & 0.300 & 0.300 & 0.300 \\
\hline Eoed & кH $/ \mathrm{M}^{2}$ & 14E04 & $\begin{array}{c}19.90 \mathrm{E} \\
3\end{array}$ & 14E04 \\
\hline $\mathrm{c}^{\prime}$ & кН/ $/ \mathrm{M}^{2}$ & 15.30 & 18.70 & 15.30 \\
\hline$\varphi^{\prime}$ & град. & 16.50 & 19.70 & 16.50 \\
\hline $\mathrm{k}_{\mathrm{X}}$ & $\mathrm{M} / \mathrm{cyT}$ & $\begin{array}{c}0.0001 \\
7 \\
\end{array}$ & $\begin{array}{c}0.0004 \\
0\end{array}$ & 0.00017 \\
\hline $\mathrm{ky}$ & $\mathrm{M} / \mathrm{cyT}$ & $\begin{array}{c}0.0001 \\
7\end{array}$ & $\begin{array}{c}0.0004 \\
0\end{array}$ & 0.00017 \\
\hline
\end{tabular}


The criterial correlation is following:

- the structure state is normal if $\mathrm{F} \leq \mathrm{K} 1$;

- the structure state is partially operational if $\mathrm{K} 1<\mathrm{FM} \leq \mathrm{K} 2$;

- the structure state is inoperative if $\mathrm{F}>\mathrm{K} 2$.

$\mathrm{F}$ is the measured (calculated from the measured) value of the indicator;

K1 - criteria of the operable state (conditions of normal operation);

$\mathrm{K} 2$ - criteria of the limiting state, when exceeded, the operation is unacceptable.

Calculations the dam slopes stability have showed that the stability coefficients are $\mathrm{K} 1=$ 1.8 for the downstream slope.

The construction of predictive models is based on the extrapolation method due to the lack of a sufficient volume of field data (service life 31 years, estimated service life 50 years) (Fig. 4).

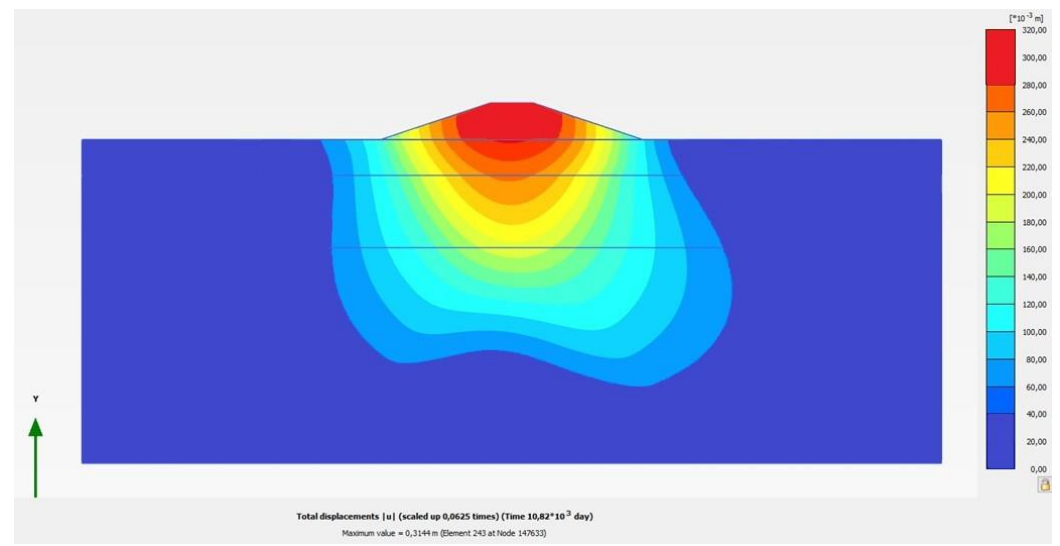

Fig. 4. Predictive model of the dam foundation and body deformations according to the consolidation model - 50 years of operation

\section{Discussion}

The breakout wave parameters during a hydrodynamic accident have determined under the following assumption: the pond dam destruction will occur at the upstream level at the height dam coping in the zone of flood discharge culvert. The lower pond and the river floodplain provide accumulation of the volume of the outflowing water.

Breakout Wave Parameters:

wave coping height $-1.0 \mathrm{~m}$,

movement speed $-1.5 \mathrm{~m} / \mathrm{s}$.

The water level height in the upstream is $5.1 \mathrm{~m}$,

the water surface's hydraulic slope is $\mathrm{i}=0.0012$.

The maximum height of flooding of the territory in the upstream is $\mathrm{h}=2.2 \mathrm{~m}$.

The duration of the flooding is 7 days.

The flooded area on the left bank is $0.3 \mathrm{~km}^{2}$.

The results of the identification of the parameters of the developed project models for the dams' typical sections are given as part of a deterministic approach, provided stabilization of the exploitation mode of the structure after 50 years of exploitation.

The risk of an accident according to possible scenarios of the development of an accident can be assessed as moderate, and the hydraulic structures level of safety, according to the terminology of the Russian register of hydraulic structures, corresponds to a reduced one. 


\section{References}

1. N. N. Kobeleva, Bulletin of SGUGiT, 2(22), 55 (2017)

2. N. N. Kobeleva and V. S. Khoroshilov Vestnik SGUGiT, 2(34) 73 (2016)

3. Xudong Qu, Jie Yang and Meng Chang Hindawi, Journal of Sensors, 1 (2019)

4. Decree of the Government of the Russian Federation No. 1108 October 27, 2012 On federal state supervision in the field of safety of hydraulic structures, http://en.gosnadzor.gov.ru/publications

5. Resolution of the Government of the Russian Federation of May 21, 2007 No. 304 On the classification of natural and technogenic emergencies, http://en.gosnadzor.gov.ru/publications

6. A. P. Krylov, A. M. Bakshtanin, E. S. Beglyarova Hydraulic engineering, 3, 22 (2021)

7. Yu. G. Ivanenko, A. M. Bakshtanin, A. A. Tkachev, D. Yu. Ivanenko Mechanization and electrification of agriculture (Moscow, 2020)

8. A. M. Bakshtanin Environmental management, 5, 57 (2008)

9. A. P. Guryev, E. S. Beglyarova, A. M. Bakshtanin, B. A. Hayek Environmental management, 5, 90 (2019)

10. A. P. Krylov, A. M. Bakshtanin, E. S. Beglyarova Environmental management, 3, 99 (2020)

11. N P Karpenko et al, IOP Conf. Ser.: Earth Environ. Sci., 723, 052006 (2021) 